\title{
Assessment of erectile function among patients with chronic kidney disease : A case-control study
}

\section{Original Article}

\author{
Nashaat N. Ismael, Emad Eldien Kamal Ali', Mohamed Abd El Fattah Farag ${ }^{3}$, Nancy \\ Endrawes Samaan ${ }^{4}$ Hany M.Saad ${ }^{5}$ \\ ${ }^{1}$ Department of Andrology and STDs, Faculty of Medicine, Beni-Seuf University, ${ }^{2}$ Department \\ of Dermatology and Andrology, Faculty of Medicine, Assiut University, ${ }^{3}$ Department of \\ Andrology, Faculty of Medicine, Cairo University, ${ }^{4}$ Department of Dermatology, Beni Suef \\ General Hospital, ${ }^{5}$ Department Andrology, Faculty of Medicine, Suez Canal University.
}

\begin{abstract}
Objective: The aim was to assess the effect of chronic kidney disease (CKD) on erectile function. Patients and Methods: This study included 40 patients on hemodialysis (HD), 40 patients on medical treatment [predialysis (PD)], and 20 controls. They were assessed using international index of erectile function questionnaire andlaboratory investigations (blood urea, serum creatinine, and both total and free testosterone).

Results: The mean age in HD patients was $42.20 \pm 5.08$ years, in PD patients was $43.83 \pm 6.59$ years, and in control group, it was $42.10 \pm 5.66$ years, with no significant difference among the three groups $(\mathrm{P}=0.383)$. Overall, $10 \%$ of HD patients had severe degree of erectile dysfunction (ED) in comparison with only $2.5 \%$ of PD patients, with no patient experiencing severe $\mathrm{ED}$ in the control group. There was a significant difference among the three groups regarding the grade of $\mathrm{ED}(P<0.001)$. The mean free testosterone levels in HD, PD, and control groups were $3.78 \pm 2.09,3.84 \pm 1.36$, and 7.36 \pm 2.33 , respectively, which showed a significant difference $(P<0.001)$. There was a statistically significant relationship between age and grade of ED in HD patients $(P=0.002)$. However, in the PD patient group, there was no relation between age and ED grade $(P=0.819)$. There was no relation between total and free testosterone levels in HD and PD patients and their ED grade $(P>0.05)$.

Conclusion: CKD has deleterious effect on erectile function which was more severe in patients on HD than those on medical treatment. Free testosterone level was significantly reduced in patients with CKD. There was a relationship between age of HD patients and severity of ED. No relationships were found between severity of ED and disease duration, serum testosterone level (total and free), blood urea, and serum creatinine in patients with CKD.
\end{abstract}

Key Words: Chronic kidney disease, erectile dysfunction, hemodialysis, testosterone.

Received: 24 October 2020, Accepted: 17 February 2021

Corresponding Author: Hany Mohammed Saad, Department of Andrology, Faculty of Medicine, Suez Canal University, Ismailia - Egypt, Tel.: 002-01223192964, E-mail: h_saad20@hotmail.com

ISSN: 2090-6048, 2021

\section{INTRODUCTION}

Chronic kidney disease (CKD) is a worldwide major health problem. Erectile dysfunction (ED) is a common condition in patients with CKD. Prevalence of ED in uremic males in predialysis (PD) stage is $9 \%$, whereas in uremic males on hemodialysis (HD) ranges from 60 to $75 \%{ }^{[1]}$. The incidence of ED in patients with severe renal disease is significantly higher in comparison with healthy men of the same age. The etiopathogenesis of ED in those patients include both organic and psychogenic factors ${ }^{[2]}$.

There are many reasons to explain the higher prevalence of ED in HD populations such as atherosclerosis, diabetes, and hypertension.These factors are associated with ED and tend to be common among patients with end-stage renal disease. Medications that are frequently used in the setting of renal disease have also been associated with ED, including several diuretics, antihypertensives, antidepressants, and $\mathrm{H} 2$ antagonists ${ }^{[3]}$.

Management of ED in patients with CKD remains difficult. Complexity of this multisystem disease needs a multidisciplinary approach for studying it. Despite improvement in the delivery of renal support, the high prevalence and the controversial views about etiopathogenesis of ED in patients with CKD, especially those on HD, motivated us to study the effect of CKD on erectile function ${ }^{[4]}$. 


\section{AIM OF THE STUDY}

The aim was to assess the effect of CKD on erectile function.

\section{PATIENTS AND METHODS}

This was a case-control study. The study included 100 males aged from 20 to 65 years. They were divided into three groups:HD patients group consisted of 40 males with CKD on HD with creatinine level more than $6 \mathrm{mg} / \mathrm{dl}$, PD patients group consisted of 40 males with CKD on medical treatment with creatinine level $2-6 \mathrm{mg} /$ $\mathrm{dl}$,and control group consisted of 20 males with normal kidney functions. The study was conducted in nephrology and dialysis unit of Beni-Suef University Hospital in Beni-Suef, Egypt during the period from January 2017 to August 2017. An approval was taken from Beni-Suef University hospital to performthe study. Informed consent was obtained from all participants before inclusion in the study. All the participants were subjected to history taking (personal, medical, sexual, and surgical history);general and genital examination; sexual function assessment, using international index of erectile function (IIEF-5) questionnaire (Appendix I); and laboratory investigations in the form of serum creatinine level (participants were selected and classified accordingly), blood urea, and serum testosterone (total and free). Exclusion criteria were patients with diabetes mellitus, liver diseases, cardiac disease, and malignancies and patients taking drugs that may affect erectile function.

\section{Statistical analysis}

Data entry and analysis were done using IBM SPSS software package, version 20.0.(IBM Corp., Armonk, New York, USA).Quantitative data were expressed as means $\pm \mathrm{SD}$, whereas qualitative data were expressed as numbers and percentages (\%). A $P$ value less than 0.05 was considered statistically significant.

\section{RESULTS}

This was a case-control study. The study included three groups: HD patients consisted of 40 males with CKD on HD with creatinine level more than $6 \mathrm{mg} / \mathrm{dl}$, PD patients consisted of 40 males with CKD on medical treatment with creatinine level $2-6 \mathrm{mg} / \mathrm{dl}$, and control group consisted of 20 males with normal kidney functions. Sexual functions were assessed using IIEF-5 questionnaire, and laboratory investigations in the form of serum creatinine, blood urea, and serum testosterone (total and free) were done for all participants.

In this study, the mean age of the three groups were comparable. The mean age in HD patients was $42.20 \pm 5.08$ years, in PD patients was $43.83 \pm 6.59$ years, and in control group was $42.10 \pm 5.66$ years. There was no statistically significant difference among the three groups regarding age $(P=0.383)$. Body Mass Indexes (BMIs) of the three groups were also comparable. The mean BMI in HD patients was $27.83 \pm 2.77$, in PD patients was $29.72 \pm 2.04$, and in control group was $27.76 \pm 1.58$. There was no statistically significant difference among the three groups concerning BMI $(P=0.620)$ (Table 1).

Table 1: Comparison amongthe study groups according to age and BMI

\begin{tabular}{lcccc}
\hline & Hemodialysis patients & Predialysis patients & Controls & $P$ value \\
\hline $\mathrm{n}(\%)$ & $40(100)$ & $40(100)$ & $20(100)$ & 0.383 \\
Age & $42.20 \pm 5.08(33.00-53.00)$ & $43.83 \pm 6.59(30-56)$ & $42.10 \pm 5.66(31-51)$ & 0.620 \\
BMI (kg/m2) & $27.83 \pm 2.77(22.23-35.41)$ & $29.72 \pm 2.04(25.4-33.31)$ & $27.76 \pm 1.58(25.34-30.85)$ & \\
\hline
\end{tabular}

Values presented as mean $\pm \mathrm{SD}$ (minimum-maximum).

The patients had significantly higher levels of urea and creatinine, which were $168.20 \pm 18.72$ and $11.881 \pm 2.129$, respectively in HD group and were 132.18 \pm 9.32 and $4.907 \pm 2.323$, respectively, in PD group, than controls, which were $20.85 \pm 6.10$ and $0.8 \pm 0.4$, respectively. The mean total testosterone levels in HD, PD, and control groups were $4.28 \pm 2.21,4.06 \pm 1.07$, and $4.22 \pm 1.16$, respectively, which showed a non-significant difference $(P=0.830)$. However, the mean free testosterone levels for the same three groups were $3.78 \pm 2.09,3.84 \pm 1.36$, and $7.36 \pm 2.33$, respectively, which showed a statistically significant difference $(P<0.001)($ Table 2$)$. 
Table 2: Comparison among the study groups according to laboratory findings.

\begin{tabular}{|c|c|c|c|c|}
\hline & Hemodialysis patients & Predialysis patients & Controls & $P$ value \\
\hline $\mathrm{n}(\%)$ & $40(100)$ & $20(100)$ & $40(100)$ & $40(100)$ \\
\hline Urea (mg/dl) & $168.20 \pm 18.72$ & $132.18 \pm 9.32$ & $20.85 \pm 6.10$ & $<0.001 *$ \\
\hline Creatinine $(\mathrm{mg} / \mathrm{dl})$ & $11.881 \pm 2.129$ & $4.907 \pm 2.323$ & $0.8 \pm 0.4$ & $<0.001 *$ \\
\hline $\mathrm{Tt}(\mathrm{ng} / \mathrm{mL})$ & $4.28 \pm 2.21$ & $4.06 \pm 1.07$ & $4.22 \pm 1.16$ & $<0.830$ \\
\hline $\mathrm{Ft}(\mathrm{ng} / \mathrm{dl})$ & $3.78 \pm 2.09$ & $3.84 \pm 1.36$ & $7.36 \pm 2.33$ & $<0.001 *$ \\
\hline
\end{tabular}

$\mathrm{Ft}$, free testosterone, laboratory findings values presented as mean $\pm \mathrm{SD} ; \mathrm{Tt}$, total testosterone.

$* P$ value is considered significant.

Regarding ED grade, the comparison among the three study groups revealed that $10 \%$ of HD patients had severe degree of ED in comparison with only $2.5 \%$ of PD patients, with no patient experiencing severe ED in the control group. There was a statistically significant difference among the three groups regarding ED grade $(P<0.001)$ (Table 3$)$.

In HD patient group, the mean age in mild ED cases was $41.15 \pm 4.81$, whereas it was $48.75 \pm 3.50$ years in severe cases. There was a statistically significant relationship between age of HD patients and their ED grade $(P=0.002)$, as older patients tended to have worse ED than younger patients. However, in PD patient group, the mean age in mild ED cases was 42.69 \pm 7.51 , whereas it was $43.71 \pm 5.09$ years in moderate ED cases, with only one severe ED case aged 50 years. We found a non-significant relationship between age of PD patients and their ED grade $(P=0.819)$.

In our study, the mean disease duration in HD patients was $50.08 \pm 15.61$ months in mild ED cases, whereas it was $54 \pm 12.11$ months in severe cases. There was no statistically significant relationship between disease duration and ED grade in HD patient group $(P=0.922)$. Moreover, in PD patient group, there was no statistically significant relationship between disease duration and ED grade $(P=0.805)$, as the mean duration of the disease was $32.25 \pm 10.14$ months in mild ED cases, whereas it was $32 \pm 9.68$ months in moderate cases, with only one severe case with 30-month disease duration.

Our results showed that there were no statistically significant relationships between total and free testosterone levels and $\mathrm{ED}$ grade in $\mathrm{HD}$ and $\mathrm{PD}$ patients $(P>0.05)$. Moreover, there were no statistically significant relationships between blood urea and creatinine levels and ED grade in HD and PD patients $(P>0.05)$ (Table 4).

Table 3: Comparison among the study groups regarding erectile dysfunction grading, according to international index of erectile function-5

\begin{tabular}{|c|c|c|c|c|}
\hline \multirow{3}{*}{ Grade of ED } & \multicolumn{3}{|c|}{ Groups } & \multirow{3}{*}{$P$ value } \\
\hline & Hemodialysis & predialysis & Control & \\
\hline & n $(\%)$ & n $(\%)$ & n $(\%)$ & \\
\hline No & $0(0.0)$ & $3(7.5)$ & $12(60.0)$ & \\
\hline Mild & $13(32.5)$ & $16(40.0)$ & $4(20.0)$ & \\
\hline Mild to Moderate & $14(35.0)$ & $13(32.5)$ & $2(10.0)$ & $<0.001^{*}$ \\
\hline Moderate & $9(22.5)$ & $7(17.5)$ & $2(10.0)$ & \\
\hline Severe & $4(10.0)$ & $1(2.5)$ & $0(0.0)$ & \\
\hline Total & $40(100.0)$ & $40(100.0)$ & $20(100.0)$ & \\
\hline
\end{tabular}

$E D$, erectile dysfunction.

$* P$ value is considered significant. 
Table 4: Relation between erectile dysfunction grading and each of age, disease duration, blood urea, serum creatinine, and total and free testosterone levels in hemodialysis and predialysis groups

\begin{tabular}{|c|c|c|c|c|c|c|}
\hline ED grade & No ED & Mild & $\begin{array}{l}\text { Mild to } \\
\text { moderate }\end{array}$ & Moderate & Severe & $\begin{array}{c}P \\
\text { value }\end{array}$ \\
\hline \multicolumn{7}{|l|}{ Age } \\
\hline HD patients & - & $41.15 \pm 4.81$ & $39.64 \pm 4.13$ & $44.78 \pm 4.12$ & $48.75 \pm 3.50$ & $0.002 *$ \\
\hline PD patients & $45.33 \pm 7.64$ & $42.69 \pm 7.51$ & $44.46 \pm 6.49$ & $43.71 \pm 5.09$ & 50 & 0.819 \\
\hline \multicolumn{7}{|c|}{ Disease duration (months) } \\
\hline HD patients & - & $50.08 \pm 15.61$ & $49.21 \pm 14.18$ & $48.56 \pm 9.88$ & $54.00 \pm 12.11$ & 0.922 \\
\hline PD patients & $32.33 \pm 7.51$ & $32.25 \pm 10.14$ & $36.38 \pm 10.70$ & $32.00 \pm 9.68$ & 30.00 & 0.805 \\
\hline \multicolumn{7}{|l|}{ Urea (mg/dl) } \\
\hline HD patients & - & $168.46 \pm 20.22$ & $170.43 \pm 17.97$ & $164.44 \pm 20.85$ & $168.00 \pm 17.20$ & 0.912 \\
\hline PD patients & $129.00 \pm 4.58$ & $136.56 \pm 8.76$ & $128.69 \pm 6.22$ & $131.00 \pm 13.98$ & 125.00 & 0.819 \\
\hline \multicolumn{7}{|c|}{ Creatinine (mg/dl) } \\
\hline HD patients & - & $12.29 \pm 0.75$ & $10.45 \pm 0.62$ & $11.59 \pm 0.98$ & $12.07 \pm 1.20$ & 0.689 \\
\hline PD patients & $5.23 \pm 0.38$ & $4.64 \pm 0.67$ & $5.13 \pm 0.54$ & $4.77 \pm 0.59$ & 5.40 & 0.171 \\
\hline \multicolumn{7}{|l|}{$\mathrm{Tt}(\mathrm{ng} / \mathrm{ml})$} \\
\hline HD patients & - & $5.16 \pm 2.18$ & $3.81 \pm 2.26$ & $3.58 \pm 2.33$ & $4.60 \pm 1.43$ & 0.311 \\
\hline PD patients & $4.30 \pm 1.1$ & $3.80 \pm 1.41$ & $4.16 \pm 0.66$ & $4.19 \pm 0.92$ & 5.10 & 0.714 \\
\hline \multicolumn{7}{|l|}{$\mathrm{Ft}(\mathrm{ng} / \mathrm{dl})$} \\
\hline HD patients & - & $3.89 \pm 1.70$ & $3.75 \pm 1.58$ & $3.42 \pm 1.71$ & $4.32 \pm 5.06$ & 0.911 \\
\hline PD patients & $3.47 \pm 2.31$ & $3.84 \pm 1.33$ & $3.97 \pm 1.18$ & $3.69 \pm 1.68$ & 4.50 & 0.960 \\
\hline
\end{tabular}

Values presented as mean $\pm \mathrm{SD}$.

ED, erectile dysfunction; Ft, free testosterone; HD, hemodialysis; PD, predialysis; Tt, total testosterone.

$* P$ value is considered significant.

\section{DISCUSSION}

Approximately $80.7 \%$ of uremic male patients complain of ED and greater percentages complain of diminished libido and marked decline in frequency of intercourse ${ }^{[5]}$.

Both age and BMI in the three study groups were comparable $(P>0.05)$. These two variables are important confounding factors regarding erectile function.

Our finding regarding the significant increase in mean levels of urea and creatinine for patients in HD and PD groups versus controls was self-evident owing to the uncompromised renal function in these patients $(P<0.001)$.

Kerstin et al. ${ }^{[6]}$ found that both total and free testosterone serum levels gradually decreased through increasing CKD stage. This partially agrees with our results as we found that free testosterone levels were significantly lower in PD and HD patients than controls $(P<0.001)$, but this was not the case for total testosterone in our study $(P>0.05)$, which may be owing to the difference in sample size.

Our data revealed a statistically significant decrease in ED grade through HD patients, PD patients, and controls, respectively. This result reflects the negative effect of CKD on erectile function. Many authors supported the opinion about the negative effect of CKD on erectile function through various pathophysiological mechanisms ${ }^{[7]}$. It is good to mention that in our study neither age nor BMI can explain this difference in erectile function between the study groups, as there was no statistically significant difference between the study groups regarding these two variables.

Age has been a matter for consideration in the origin of ED. In this study, there was no statistically significant relationship between age of PD patients and severity of ED (according to IIEF-5), whereas there was a statistically significant relationship between age of HD patients and severity of $\operatorname{ED}(P=0.002)$. A study done by Cerqueira et al. ${ }^{[8]}$ showed that when age was evaluated in association with other variables in the logistical regression analysis, it remained as the factor most strongly associated with ED in HD patients, which agrees with our results.

In this study, there was no statistically significant relationship between duration of CKD and severity of ED in both studied groups. Several studies agree with this result revealing that there was no relationship between the duration of dialysis and the severity of ED. In their study, Cerqueira et al. ${ }^{[8]}$ compared patients who had been on dialysis for fewer than 3 months with those who had been on dialysis for more than 3 months and found no difference 
regarding the ED complaints between the two groups.

We found statistically nonsignificant relationships between blood urea and serum creatinine levels and ED grade in $\mathrm{HD}$ and $\mathrm{PD}$ patients $(P>0.05)$. This was discordant with the results of Ali et al. ${ }^{[9]}$ who found that blood urea and serum creatinine levels have significant correlations $(\mathrm{r}=-0.5974, P<0.001$, and $\mathrm{r}=-0.5804, P<0.001$, respectively) with the presence of ED among HD patients. This contrast may be attributed to the smaller sample size in our study.

The role of hormonal disturbances on development of ED in uremic patients is incompletely understood. No improvement of libido or potency with administration of testosterone has been reported ${ }^{[10]}$

In our study, there was no statistically significant relationship between total and free testosterone levels of patients in both HD and PD groups and ED grade $(P>0.05)$. This comes in agreement with the study of Paolo et al. ${ }^{[11]}$, who followed a group of 13 patients with CKD who had an average age of 41 years for 18 months and complaints of ED for about 6 months; they found that testosterone levels suffered negligible variations, from 3 to $2.8 \mathrm{ng} /$ ml. Simultaneously, the authors noted that ED complaints began mainly within the first 3 months after the start of treatment, thus demonstrating the lack of association between endocrine alterations and ED in patients with $\mathrm{CRF}^{[11]}$. This also is congruent with a comparative study of Cerqueira et al. ${ }^{\left[{ }^{8]}\right.}$ on patients who had been on dialysis for more and less than 3 months, as they found no association between ED complaints and levels of testosterone.

\section{CONCLUSION}

In conclusion, $\mathrm{CKD}$ has deleterious effect on erectile function, which is more severe in patients on HD than patients on medical treatment. Free testosterone level was significantly reduced in patients with CKD. There was a relationship between age of HD patients and severity of ED. No relationships were found between severity of ED and duration of CKD, serum testosterone level (total and free),blood urea, and serum creatinine in patients with CKD.

\section{LIMITATIONS}

The sample size was small and lacked randomization; moreover, assessments of participants using psychological tests were not accomplished.

\section{CONFLICT OF INTEREST}

There are no conflicts of interest.

\section{REFERENCES}

1. Suzuki E, Nishimatsu H, Oba S, Takahashi M, Homma Y. Chronic kidney disease and erectile dysfunction. World J Nephrol2014; 3:220-229.

2. Tian Y, Zheng-Guo J, Tang Y, Zhang L, Lu W, Lin $\mathrm{J}$, et al. Prevalence and influential factors of erectile dysfunction in male renal transplant recipients: a multiple center survey. Chin Med J2008; 121:795-799.

3. McVary K. Clinical practice. Erectile dysfunction. N Engl J Med2007; 357:2472-2481.

4. Manish R, Raja R. Sexual and gonadal dysfunction in chronic kidney disease: pathophysiology. Indian J Endocrinol Metab2012; 16:214-219.

5. Arslan D, Aslan G, Sifil A, Cavdar C, Celebi I, GamsariT, EsenA. Sexual dysfunction in male patients on hemodialysis: assessment with the International Index of Erectile Function (IIEF). Int JImpot Res2002; 14:539-542.

6. Kerstin S, Marie N, Hylander B, Mikael L. Sexual function and testosterone level in men with conservatively treated chronic kidney disease. Am J Mens Health2017;11:1069-1076.

7. Eirini P, Anna V, Antonios L, Chrysoula B, MichaelD. Erectile dysfunction in chronic kidney disease: from pathophysiology to managementWorld J Nephrol2015; 4:379-387.

8. Cerqueira J, Moraes M, Glina S. Erectile dysfunction: prevalence and associated variables in patients with chronic renal failure. Int J Impot Res2002; 14:65-71.

9. Ali M, Abdel-Hafez H, Mahran A, Mohamed H, Mohamed E, El-Shazly A, Gadallah A, Abbas M. Erectile dysfunction in chronic renal failure patients undergoing hemodialysis in Egypt. Int $\mathbf{J}$ Impot2005; 17:180-185.

10. Barton H, Mirahmadi K, Vaziri D. Effects of long-term testosterone administration on pituitary-testicular axis in end stage renal failure. Nephron1982; 31:61-64.

11. PaoloN, CapotondoL, GaggiottiE, RossiP. Sexual function in uremic patients. Contrib Nephrol 1990; 77:34-44. 
Appendix I

\section{(sHiм (الدليل الدولي للاختلال الوظيفي ألا نتصابى )}

بان مغصل عن العهة الخيسة للرجال

$$
\text { لمانم المريض : }
$$

\section{:}

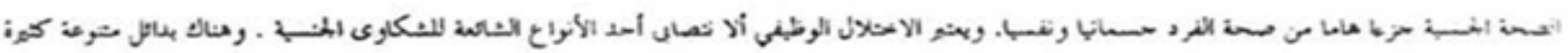

\begin{tabular}{|c|c|c|}
\hline \multicolumn{2}{|c|}{ 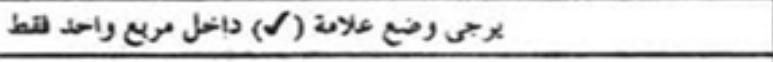 } & خلال الأسائع أل ألانية \\
\hline $\begin{array}{l}(*) \\
(t) \\
(r) \\
(x) \\
(i)\end{array}$ & 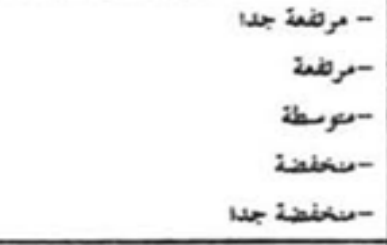 & 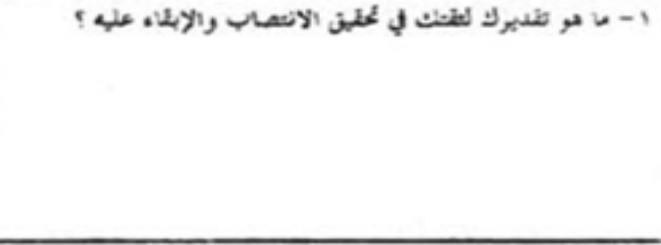 \\
\hline $\begin{array}{l}(*) \\
(i) \\
(r) \\
(T) \\
(i) \\
(\cdot)\end{array}$ & 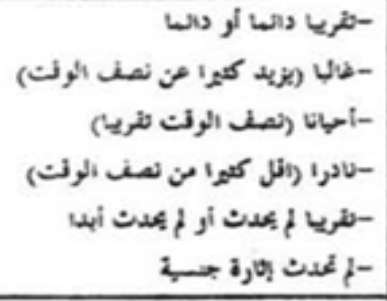 & 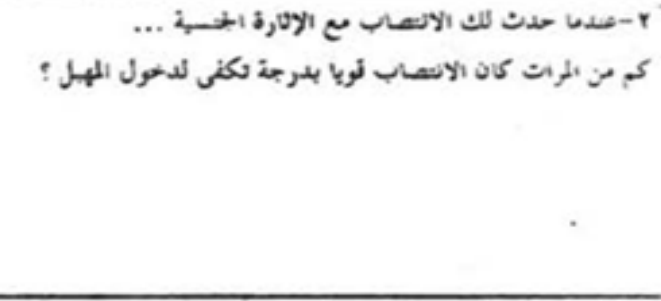 \\
\hline $\begin{array}{l}(*) \\
(\mathrm{i}) \\
(\mathrm{r}) \\
(\mathrm{i}) \\
(\mathrm{i}) \\
(+)\end{array}$ & 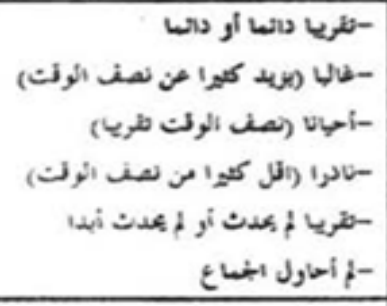 & 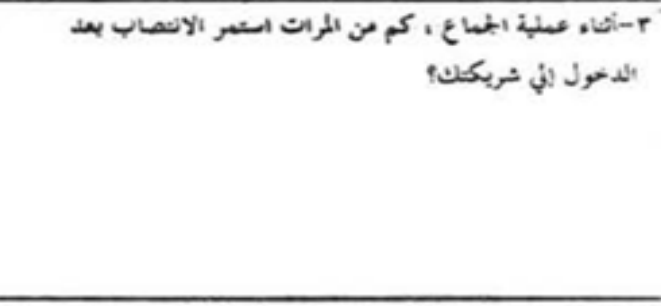 \\
\hline $\begin{array}{l}((x) \\
(\mathrm{i}) \\
(\mathrm{r}) \\
(\mathrm{r}) \\
(\mathrm{i}) \\
(\mathrm{r})\end{array}$ & 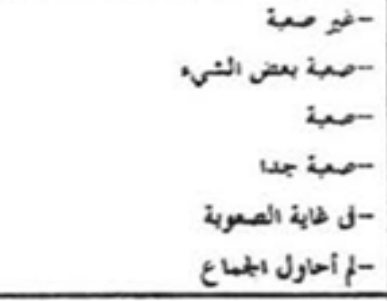 & 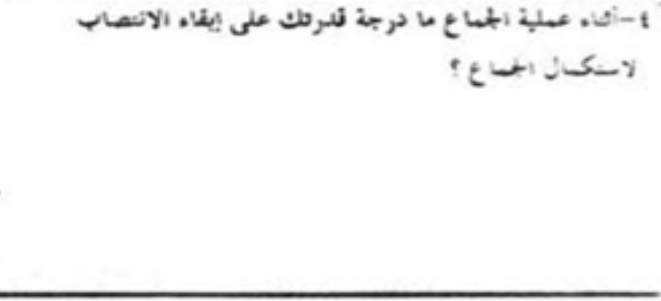 \\
\hline $\begin{array}{l}(\cdot) \\
(t) \\
(r) \\
(T) \\
(i) \\
(\cdot)\end{array}$ & 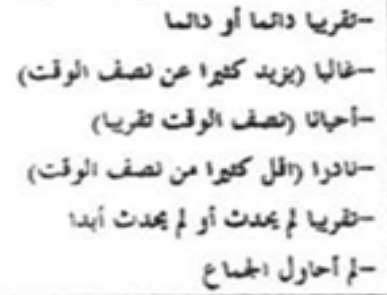 & 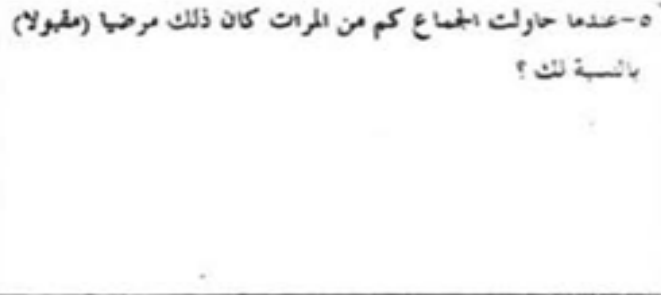 \\
\hline
\end{tabular}

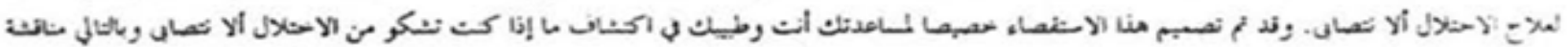

